\title{
A Novel Mechanism of PPAR Gamma Induction via EGFR Signalling Constitutes Rational for Combination Therapy in Bladder Cancer
}

\author{
Jose Joao Mansure, Roland Nassim, Simone Chevalier, Konrad Szymanski, Joice Rocha, Saad Aldousari, \\ Wassim Kassouf*
}

McGill Urologic Oncology Research, Division of Urology, McGill University Health Center, Montreal, Quebec, Canada

\begin{abstract}
Background: Two signalling molecules that are attractive for targeted therapy are the epidermal growth factor receptor (EGFR) and the peroxisome proliferator-activated receptor gamma (PPAR $\gamma$ ). We investigated possible crosstalk between these 2 pathways, particularly in light of the recent evidence implicating PPAR $\gamma$ for anticancer therapy.

Principal Findings: As evaluated by MTT assays, gefitinib (EGFR inhibitor) and DIM-C (PPAR $\gamma$ agonist) inhibited growth of 9 bladder cancer cell lines in a dose-dependent manner but with variable sensitivity. In addition, combination of gefitinib and DIM-C demonstrated maximal inhibition of cell proliferation compared to each drug alone. These findings were confirmed in vivo, where combination therapy maximally inhibited tumor growth in contrast to each treatment alone when compared to control $(p<0.04)$. Induction of PPAR $\gamma$ expression along with nuclear accumulation was observed in response to increasing concentrations of gefitinib via activation of the transcription factor CCAT/enhancer-binding protein- $\beta$ (CEBP- $\beta$ ). In these cell lines, DIM-C significantly sensitized bladder cancer cell lines that were resistant to EGFR inhibition in a schedule-specific manner.
\end{abstract}

Conclusion: These results suggest that PPAR $\gamma$ agonist DIM-C can be an excellent alternative to bladder tumors resistant to EGFR inhibition and combination efficacy might be achieved in a schedule-specific manner.

Citation: Mansure JJ, Nassim R, Chevalier S, Szymanski K, Rocha J, et al. (2013) A Novel Mechanism of PPAR Gamma Induction via EGFR Signalling Constitutes Rational for Combination Therapy in Bladder Cancer. PLoS ONE 8(2): e55997. doi:10.1371/journal.pone.0055997

Editor: Aamir Ahmad, Wayne State University School of Medicine, United States of America

Received September 21, 2012; Accepted January 3, 2013; Published February 8, 2013

Copyright: (c) 2013 Mansure et al. This is an open-access article distributed under the terms of the Creative Commons Attribution License, which permits unrestricted use, distribution, and reproduction in any medium, provided the original author and source are credited.

Funding: This study was supported by the Cancer Research Society. (http://www.src-crs.ca/en-CA) W. Kassouf is a recipient of a clinical research scholar award from the FRSQ. (http://www.frsq.gouv.qc.ca/en/index.shtml). The funders had no role in study design, data collection and analysis, decision to publish, or preparation of the manuscript.

Competing Interests: The authors have declared that no competing interests exist.

*E-mail: wassim.kassouf@muhc.mcgill.ca

\section{Introduction}

Almost all patients with metastatic bladder cancer succumb to disease, with median survival of 18 months even with the best available chemotherapeutic regimens. As understanding of biology of urothelial carcinoma (UC) improves, novel approaches need to be studied. Two signalling molecules that are attractive for targeted therapy are the epidermal growth factor receptor (EGFR) and the peroxisome proliferator-activated receptor $\gamma(\operatorname{PPAR} \gamma)$. Inhibition of EGFR function is extremely attractive among the wide array of biological targets implicated in urothelial carcinoma (UC) progression. Although mechanism by which EGFR regulates tumor biology in bladder cancer is not clearly defined, it has been demonstrated that EGFR signalling regulates cell survival, proliferation, differentiation, and invasion [1]. Moreover, EGFR is implicated in tumor-induced angiogenesis and metastasis [2]. However, clinical trials with EGFR inhibitors in head and neck, lung, and colon cancer demonstrated that only a minority of patients seemed to benefit from this approach. In context of Non Small Cancer Lung Cells (NSCLC), it was shown that clinical responses were linked to activating mutations within EGFR tyrosine kinase domain, suggesting that better understanding of biological effects of EGFR inhibitors on cancer will help identify tumors that will respond to therapy [3,4]. Although none of 17 human UC cell lines nor any of 75 primary tumors evaluated at M. D. Anderson Cancer Center contained activating EGFR kinase domain mutations [5], EGFR inhibitors blocked cell cycle progression in 6/17 UG cell lines. We have shown that high EGFR expression is associated with an aggressive phenotype [6] and that modulation of GSK-3 $\beta$ might be a predictor of response to EGFR inhibitors in bladder cancer [7]. We do believe that EGFR remains a strong signalling axis in progression of bladder cancer where its inhibition may benefit selected patients.

Another receptor of interest is $\operatorname{PPAR} \gamma$, a ligand-activated receptor and a member of the nuclear receptor superfamily of transcription factors $[8,9]$. Importantly, $\operatorname{PPAR} \gamma$ plays an important role in carcinogenesis. PPAR $\gamma$ is highly expressed in tumor samples from different sites, including bladder cancer (reviewed in reference [10]). PPAR $\gamma$ is an interesting target for cancer therapy not only because of its elevated expression in tumors, but also because PPAR $\gamma$ activation results in decreased cell proliferation, decreased $\mathrm{G}_{0} / \mathrm{G}_{1}$ to $\mathrm{S}$ phase progression, increased terminal 
differentiation, and apoptosis [11,12,13]. Further, PPAR $\gamma$ agonists are potent angiogenesis inhibitors in vitro and in vivo, in part due to downregulation of VEGF $[14,15]$. Recently, a new class of PPAR $\gamma$ agonists, 1,1-bis( $3^{\prime}$-indolyl)-1-( $p$-substitutedphenyl)methanes (PPAR $\gamma$-active DIM-Cs), has been developed and shown to be significantly more potent than the previous generation of drugs. We published the first report on significant antitumorigenic activity of PPAR $\gamma$-active DIM-Cs in UG cells in vitro and in vivo [16]. Use of potent PPAR $\gamma$-active DIM-Cs was attractive and warrants further evaluation in treatment of UC.

A prior study has shown that $\operatorname{PPAR} \gamma$ agonists increase gefitinib's antitumor activity, possibly mediated through induction of PTEN expression in vitro [17]. Additionally, curcumin was shown to induce PPAR $\gamma$ expression and inhibit proliferation in hepatic stellate cells [18]. Others have shown that curcumin can also inhibit EGFR activation and these findings further corroborate the potential crosstalk between the two signaling axes of interest.

The aim of this study is to investigate crosstalk between these two signalling axes as they share some common downstream signalling effectors and evaluate whether combination of PPAR $\gamma$ agonist and an EGFR inhibitor may overcome resistance to EGFR therapy in bladder cancer.

\section{Materials and Methods}

\section{Cell Culture}

The UC cell line 253J B-V was generated from the 253J human UC cell line as previously described [19] and was kindly provided by Dr Colin P.N. Dinney from M.D. Anderson Cancer Center, Houston, Texas. The UM-UC series of urothelial carcinoma cell lines used in this study were genotypically characterised and provided by the Specimen Core of the Genitourinary Specialized Programs of Research Excellence in bladder cancer at M. D. Anderson Cancer Center [20].

\section{Drugs}

Gefitinib (Iressa ZD1839) was supplied by AstraZeneca, London, United Kingdom) and the orally available PPAR $\gamma$-active DIM-C was generously provided by Dr. S. Safe, Houston, TX as dry powder.

\section{Cell Proliferation Assay}

Bladder cancer cells were treated with different concentrations of gefitinib $(0.001 \mu \mathrm{M}$ to $100 \mu \mathrm{M})$ and DIM-C $(0.01 \mu \mathrm{M}$ to $10 \mu \mathrm{M}$ ) in EMEM's supplemented with $10 \%$ FBS for 48 hs Cell proliferation was evaluated using MTT assays (Sigma-Aldrich, Canada). The GI50 value was defined as the mean concentration of drug that generated $50 \%$ of growth inhibition.

\section{Western Blot Analysis}

Cells were harvested at $\sim 75 \%$ to $80 \%$ confluence in lysis buffer (RIPA) and a cocktail of phosphatase and protease inhibitors (Roche Diagnostics, Germany). Proteins were subjected to SDSPAGE, transferred onto nitrocellulose membranes (Bio-Rad, Hercules, CA) by semidry electroblotting. Primary monoclonal antibodies [EGF Receptor (15F8), tubulin and b-actin (Cell Signaling Technology, New England, MA)] and PPAR $\gamma$ (sc7273, Santa Cruz Biotechnology, California, US) were applied to detect bands of interest. Additionally, the following rabbit antibodies from cell signaling were used : Akt; phospho-Akt (Ser473); GSK-3 $\beta$; phospho-GSK-3 $\beta$ (Ser9); p21 Waf1/Cip1; p44-42 MAPK (Erk1/2); phosphor-p44/42 MAPK (Erk1/2). Anti-rabbit and anti-mouse immunoglobulins (IgGs) coupled to
HRP/horseradish were used as secondary antibodies according to the primary antibody.

\section{Immunofluorescence}

Cells cultured in eight-well plastic chambers were washed on ice with cold PBS containing protease inhibitors (Roche Diagnostics, Germany) and fixed with $3.7 \%$ paraformaldehyde. Cells were incubated with different concentrations of gefitinib $(0,2,4$ and $8 \mu \mathrm{M})$ for $24 \mathrm{hs}$ and then incubated with mouse monoclonal PPAR $\gamma$ primary antibody (1:50) overnight. Immunofluorescence was revealed using anti-mouse antibodies coupled to FITC (Alexa Fluor 488) or rhodamine (CY3; Invitrogen). 4,6-Diamidino-2phenylindole (DAPI) was used to stain the nuclei. Photomicrographs were taken with an inverted Olympus IX-81 microscope equipped with a CoolSnap HQ digital camera and the ImagePro+ software (version 5.0.1; Media Cybernetics).

\section{RNA Isolation and Real Time PCR}

Total RNA was extracted from cells using Trizol reagent (Invitrogen, Carlsbad, CA), according to the protocol provided by the manufacturer. The synthesis of cDNA was performed using the Quantitec Reverse Transcription Kit (Qiagen, Mississauga, ON). For RT-PCR amplification, validated primers from Qiagen (Hs_CEBPB_2_SG QuantiTect Primer Assay QT00998494) were used. No genomic DNA contamination or pseudogenes were detected by PCR without the reverse transcription step in the total RNA used. $\beta$ actin was used as an internal control. The reactions started at $95^{\circ} \mathrm{C}$ for $10 \mathrm{~min}$, followed by 40 cycles of $95^{\circ} \mathrm{C}$ for $10 \mathrm{~s}$, $60^{\circ} \mathrm{C}$ for $20 \mathrm{~s}$. Melting peaks of PCR products were determined by heat-denaturation over a $35^{\circ} \mathrm{C}$ temperature gradient at $0.2^{\circ} \mathrm{C} / \mathrm{s}$ from 60 to $95^{\circ} \mathrm{C}$. The cycle numbers crossing an arbitrary threshold $(C \mathrm{t})$ were determined using MyIQ system software, version 1.0.410 (BioRad, CA, U.S.A.). Fold change in target mRNA relative to $\beta$ actin was calculated as follow: Fold change $=2^{-\Delta \Delta C \mathrm{t}}$ where $\Delta \Delta C \mathrm{t}=(C \mathrm{t} \text { target }-C \mathrm{t} \beta \text { actin })_{\text {time }} x-(C \mathrm{t}$ target - Ct $\beta$ actin) time o Time $X$ is time point after 3 hs gefitinib. Time 0 represents the experiment starting time (no drug added).

\section{Bladder Tumor Xenografts}

Female nude mice (purchased from Charles Rivers, Wilmington, MA) were injected subcutaneously with the KU-7 cells $\left(10^{6}\right.$ cells per injection). Animals of each series (10 mice per group) were randomised and assigned to treatment and a placebo arms. DIM-C was given $60 \mathrm{mg} / \mathrm{kg} 3$ times per week and gefitinib was given $2 \mathrm{mg} /$ day, 5 times per week. All drugs and placebo were given by oral gavage. Treatment was continued for 4 weeks and subsequently tumors were harvested and weighted. Tumors were snap-frozen in liquid nitrogen for further analysis.

This study was carried out following the Standard Operating Procedures for Care and Use of Laboratory Animals of the McGill University Animal Care Committee. The protocol was approved by the Facility Animal Care Committee of the Research McGill University Health Center (Permit Number: 5428). All surgery was performed under sodium pentobarbital anesthesia, and all efforts were made to minimize suffering.

\section{Immunohistochemistry}

Serial sections of tumor xenografts from mice treated with placebo and combination treatment (gefitinib plus DIM-C) were incubated overnight at $4^{\circ} \mathrm{C}$, with primary specific antibodies against PPAR $\gamma$ (sc-7273 mouse monoclonal $\mathrm{IgG}_{1}$ antibody 1:1000 dilution, Santa Cruz, CA, USA), p21 (12D1 rabbit antibody 1:100 dilution, cell signaling, MA, USA). Goat polyclonal anti-rabbit 
A
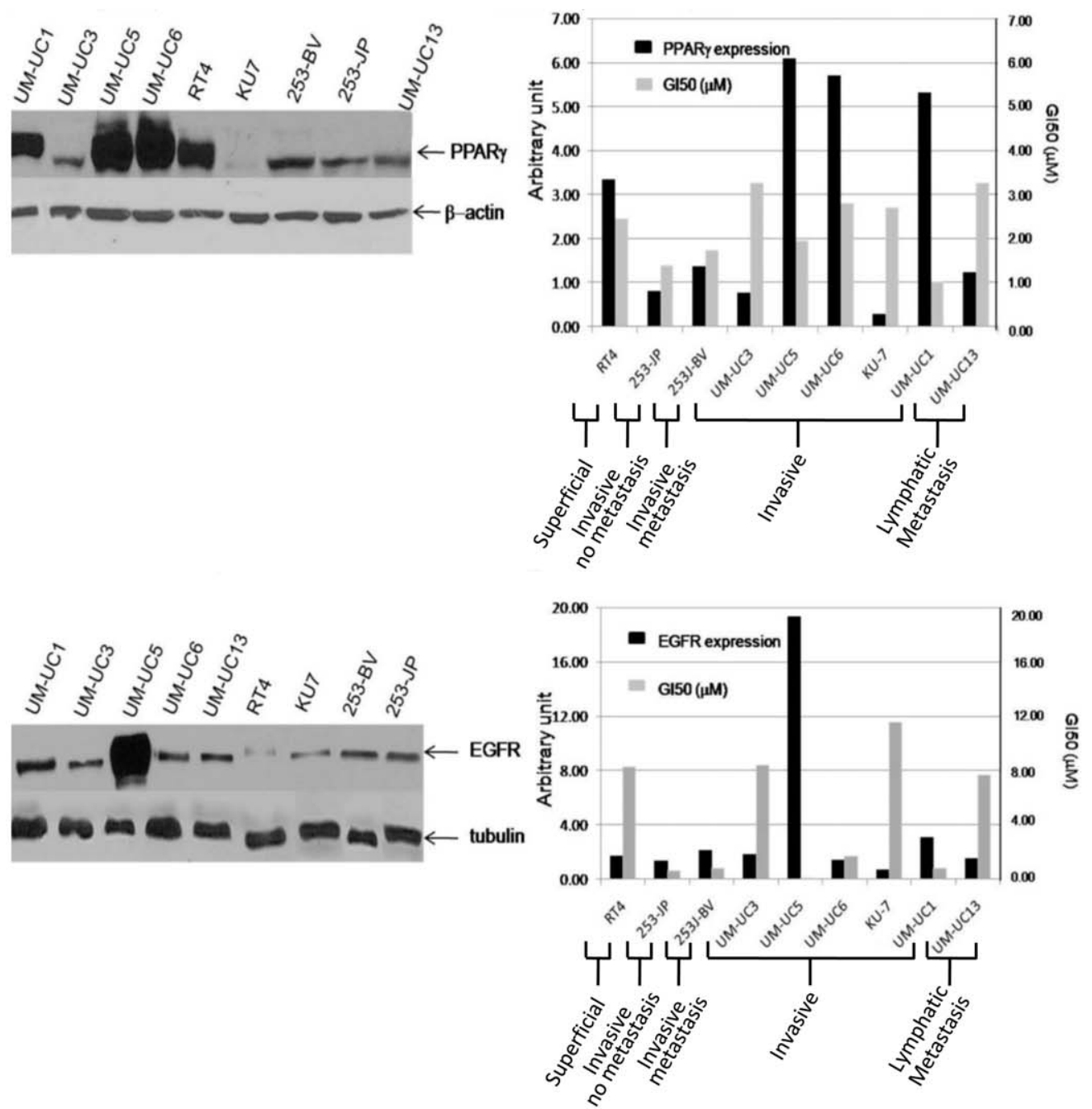

B
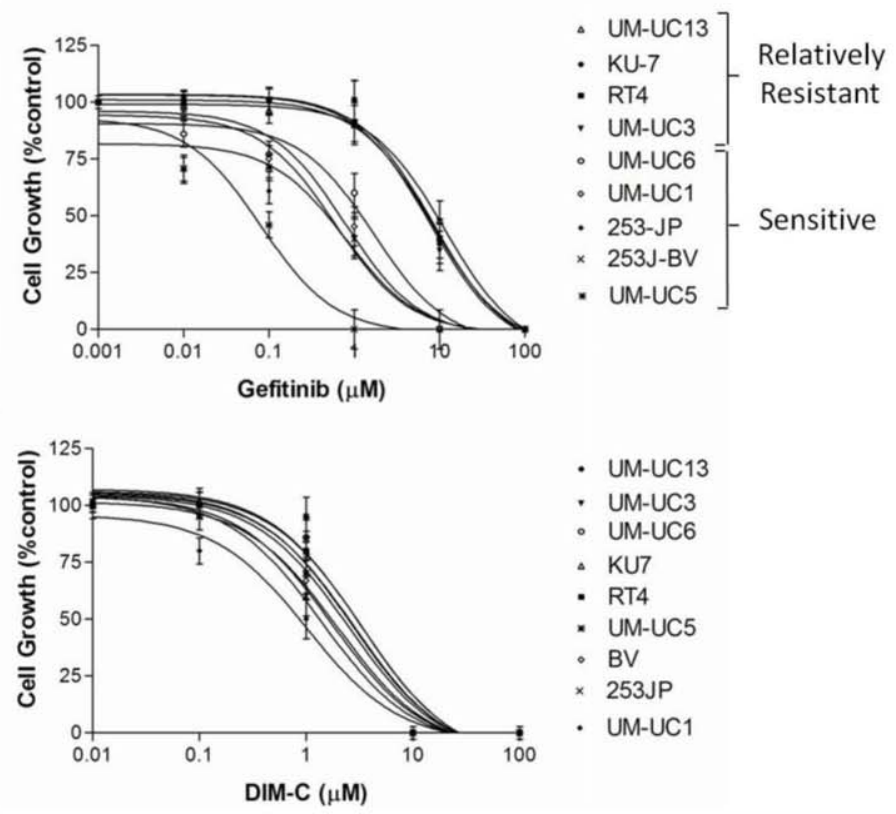
Figure 1. Baseline expression of PPAR $\gamma$ and EGFR. (A) Expression of PPAR $\gamma$ and EGFR relative to endogenous levels of $\beta$-actin and tubulin, respectively, and represented in units among 9 bladder cancer cell lines reflecting different stages of the disease (from Superficial to Invasive $\&$ no Metastasis, Invasive and Lymphatic Metastasis). (B) Dose-response of bladder cancer cell lines to PPAR $\gamma$ agonist (DIM-C) and EGFR inhibitor (gefitinib). The GI50 value was defined as the mean concentration of drug that generates $50 \%$ of growth inhibition as compared to controls.

doi:10.1371/journal.pone.0055997.g001

IgG secondary antibody, conjugated with HRP was added and incubated for $1 \mathrm{~h}$ at room temperature. Color development was performed with DAB substrate (Sigma Aldrich, Canada), according to manufacturer's instructions. Immunostaining was evaluated in a semiquantitative method based on the average of five foci on percentage of viable cells showing positive expression. Specimens were scored based on the intensity of antibody nuclear and cytoplasmic staining in each slide. Values were compared using unpaired Student's t test.

\section{Microarray Analysis}

Bladder tumors xenografts, were sectored stained by hematoxilin and eosin and the tumors were mapped for further isolation. Total RNA was extracted as previously described. RNA was quantified using a NanoDrop-ND1000 spectrophotometer (Thermo Fisher Scientific, Wilmington, DE) and quality was monitored with the Agilent 2100 Bioanalyzer (Agilent Technologies, Genome Quebec Innovation Center, CA ). Microarray analyses were performed at McGill University and Genome Quebec Innovation Center, using Illumina BeadArray ${ }^{\mathrm{TM}}$ technology. The HumanHT-12 Expression BeadChip ${ }^{\text {TM }}$ was used and contained more than 22,000 probes from the NCBI RefSeq database, which provides higher throughput processing of 12 samples per chip. There is a coverage of $>99.99 \%$ of all bead types on any given HumanHT-12. TotalPrep RNA Amplification kit from Ambion was used to perform one round of amplification from 50-500 ng of total RNA. The cDNA synthesis and in vitro transcription amplification were followed by hybridization. The BeadChips were imaged using Illumina's BeadArray or iScan reader. Statistical analysis and visualization of data from microarray experiments was performed using the software package
FlexArray version 1.6 developed and provided by Genome Quebec. Functional and signalling pathway analyses were assessed using Ingenuity Pathway Analysis (IPA) software.

\section{Statistical Analysis}

All data were analyzed using the STATA version 10.0 software. Results from in vivo were compared using repeated measure ANOVA and Fischer's exact test. $\mathrm{P}<0.05$ was considered to be statistically significant.

\section{Results}

\section{Baseline Expression of PPAR $\gamma$ and EGFR in a Panel of Urothelial Carcinoma Cell Lines}

We have previously reported that inhibition of EGFR signalling axis and activation of PPAR $\gamma$ axis are both effective in significantly inhibiting proliferation of human carcinoma cells through different pathways, in part converging to PI3K/Akt, cyclin D1, and cyclindependent kinase inhibitors $[7,16]$. In our previous work, we have shown significant expression of the HER family members across various UC cell lines [7]. To further investigate for interaction between the two signalling axes, we first screened to characterize the levels of EGFR and PPAR $\gamma$ expression across a panel of $9 \mathrm{UC}$ cell lines. As revealed in Figure $1 \mathrm{~A}$, all the cell lines tested expressed various levels of EGFR and PPAR $\gamma$. We did not demonstrate a correlation between baseline levels of expression and stage of disease of which the 9 cell lines were derived from (from superficial to invasive to metastatic). We have also determined the dose response of among the urothelial carcinoma cell lines (UM-UC1, UM-UC3, UM-UG5, UM-UC6, UM-UC13, RT4, 253JP, 253J-BV, KU7) to different concentrations of EGFR

\section{KU7-Gefitinib $5 \mu \mathrm{M}+$ DIM-C $3 \mu \mathrm{M}$}

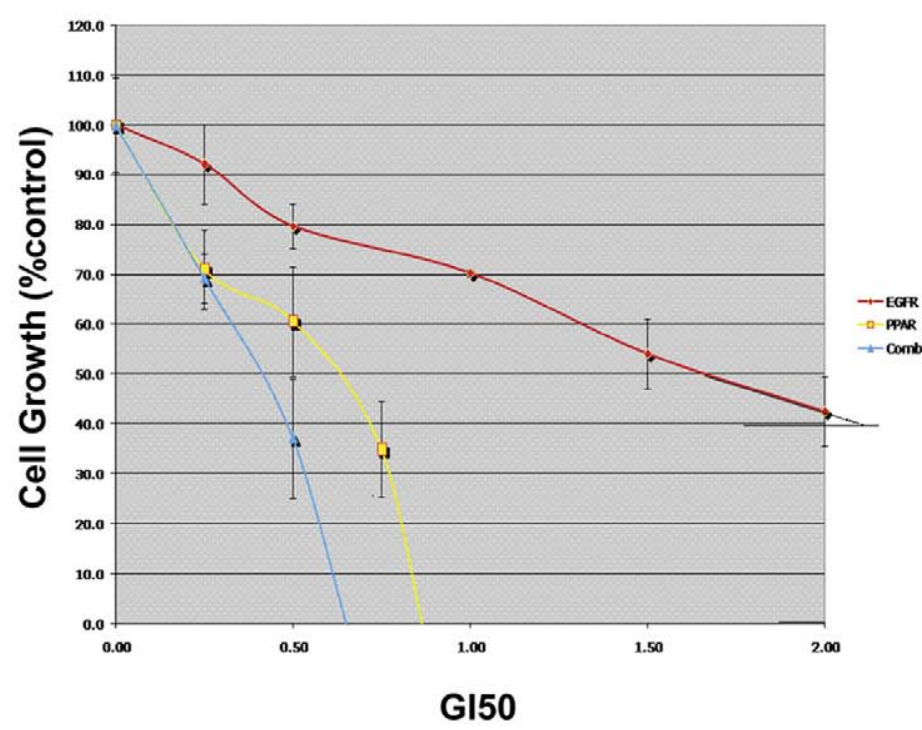

UM-UC13 Gefitinib $5 \mu M+$ DIM-C $3 \mu M$

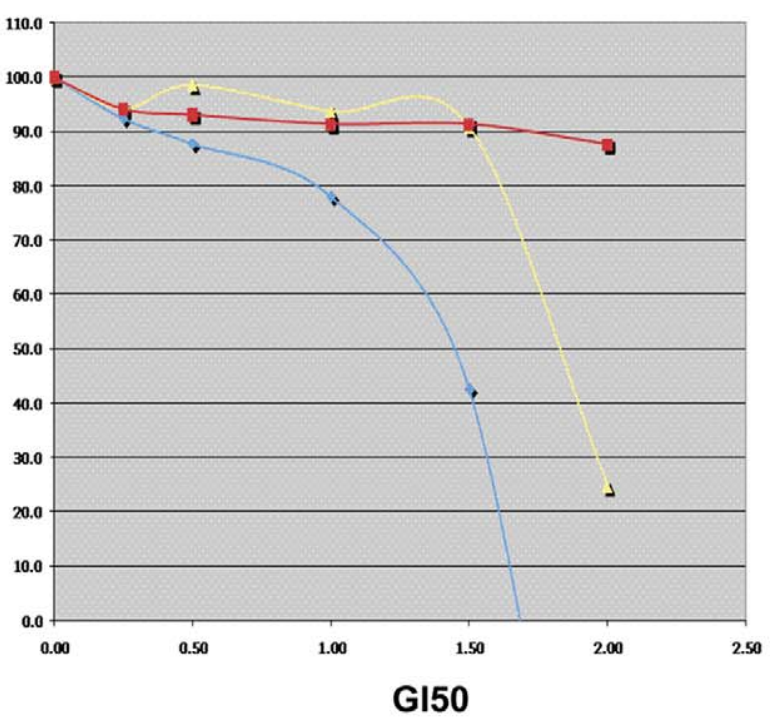

Figure 2. Antiproliferative effects of combined therapy. Growth was monitored by MTT assays. Cells were treated with gefitinib $5 \mu \mathrm{M}$ and DIM-C $3 \mu \mathrm{M}$ and compared to each drug alone. Red: gefitinib; Yellow: DIM-C; Blue: gefitinib+DIM-C. doi:10.1371/journal.pone.0055997.g002 


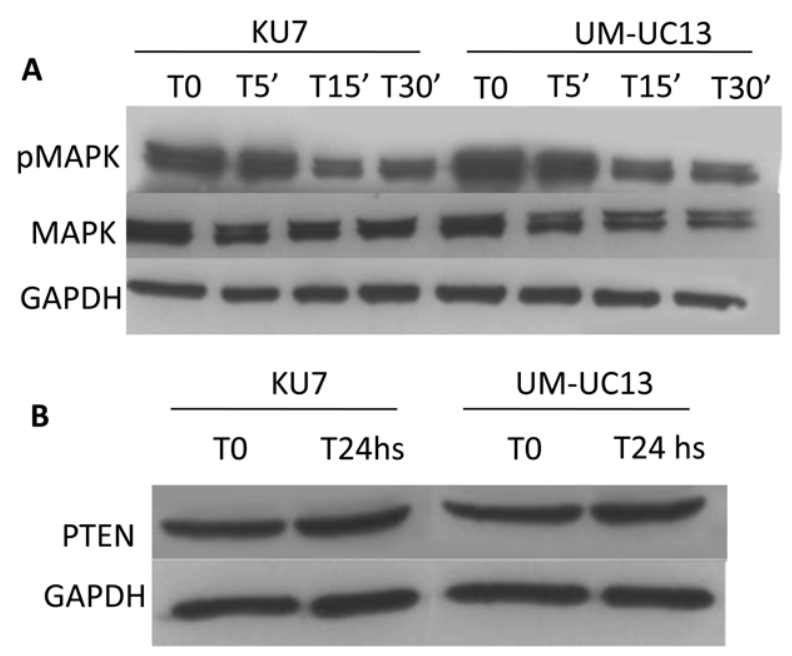

Figure 3. Effect of combination therapy on EGFR downstream signaling. (A) Phosphorylation pattern of p42/44 MAPK (Erk1/2) in cells treated with gefitinib $5 \mu \mathrm{M}$ and DIM-C $3 \mu \mathrm{M}$ for 5,15 and 30 minutes. TO is the untreated control. Whole-cell lysates were immunoblotted with phosho-p42/44 MAPK and p42/44 MAP. GAPDH was used as loading control on the Western blotting. (B) Comparison of PTEN expression in cell lines treated with gefitinib $5 \mu \mathrm{M}$ and DIM-C $3 \mu \mathrm{M}$ for $24 \mathrm{hs}$. T0 is the untreated control.

doi:10.1371/journal.pone.0055997.g003

inhibitor (gefitinib) and PPAR $\gamma$ agonist (DIM-C) after $72 \mathrm{hs}$ of treatment (Figure 1 B). We were able to stratify several UC cell lines ranging from highly sensitive to relatively resistant to EGFR inhibition, while no significant changes were observed to justify a stratification in response to DIM-C. Of note, UC5, the most sensitive cell line to gefitinib, is different from the rest of the cell lines as it contains EGFR gene amplification.

\section{Effects of Combined EGFR Inhibitors and PPAR $\gamma$ Agonists Therapy}

We investigated the antiproliferative effects of combined therapy, gefitinib and DIM-C, compared to each drug alone on bladder cancer cell growth in vitro. Growth and cell proliferation were monitored by MTT assays and conducted on two relatively EGFR-resistant cell lines (KU7 and UM-UC13). Cells were treated for $72 \mathrm{hs}$ and used a fixed-ratio of different fractions of GI50 (0.25, 0.5, 1.0 and 2.0) of each drug alone according to median effect method. Maximal inhibition of cell proliferation was demonstrated in the combined treatment compared to either drug alone (Figure 2). DIM-C rendered the resistant cells sensitive to EGFR inhibition.

\section{Effect of Combination on the EGFR Downstream Signaling and PTEN Expression}

Binding of EGFR to its ligand leads to activation of various signals, including the Ras/Raf/mitogen-activated protein kinase pathway (MAPK) [21]. Therefore, we investigated the effect of combination in the phosphorylation status of p42/44 MAPK (Erk1/2). As seen in Figure 3A, a significant time course deactivation of the Erk pathway was observed, compared to control, among cells treated with gefitinib $5 \mu \mathrm{M}$ and DIM-C $3 \mu \mathrm{M}$. Additionally, as previously mentioned, expression of PTEN increases in non-small cell lung cancer (NSGLG) treated with the PPAR $\gamma$ agonists, rosiglitazone [17]. Therefore, we also investigated the effect of combination treatment in PTEN expression. As shown in Figure 3B, no difference in PTEN expression was observed, as compared to control, when cells were treated with combined gefitinib and DIM-C for 24 hs.

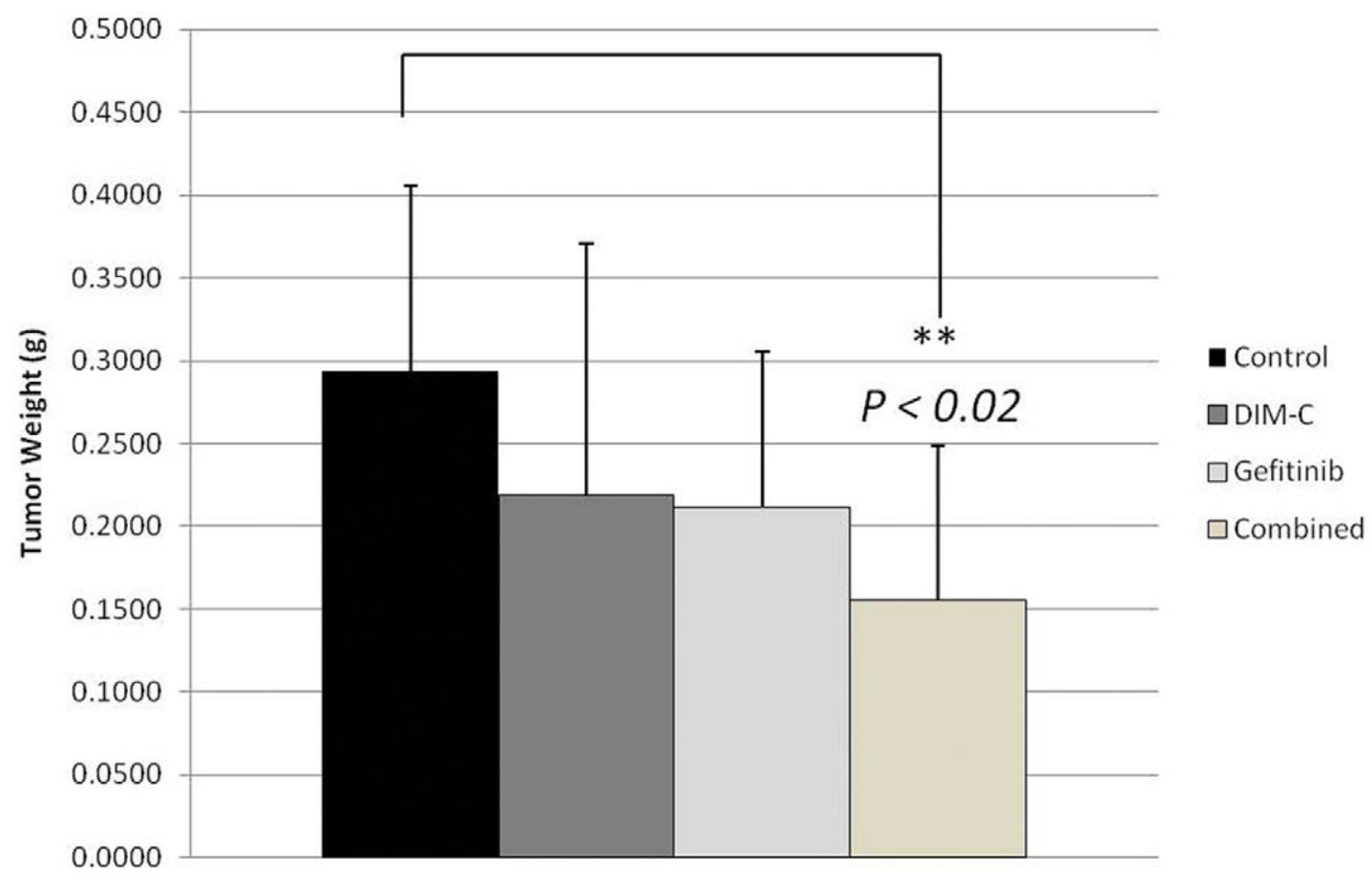

Figure 4. Effects of combination therapy in vivo. Bladder tumor growth of combination treatment arm compared to control arm ( $P<0.02)$. Ten mice per group were treated with placebo; DIM-C was given $60 \mathrm{mg} / \mathrm{Kg} 3$ times per week; Gefitinib was given 2 mg/day, 5 times per week. All drugs were administrated by oral gavage. Treatment was continued for 4 weeks.

doi:10.1371/journal.pone.0055997.g004 


\section{A}

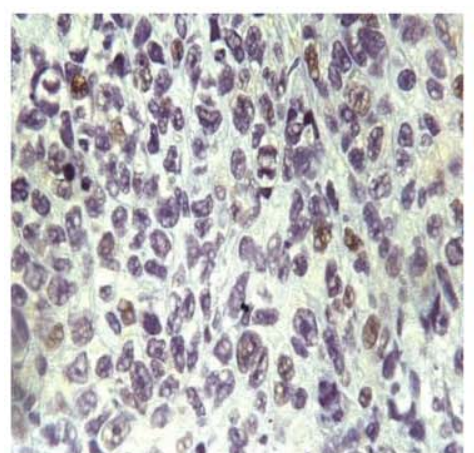

Placebo

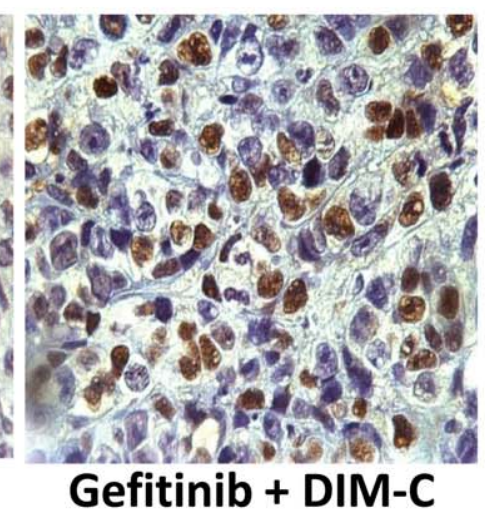

Gefitinib + DIM-C

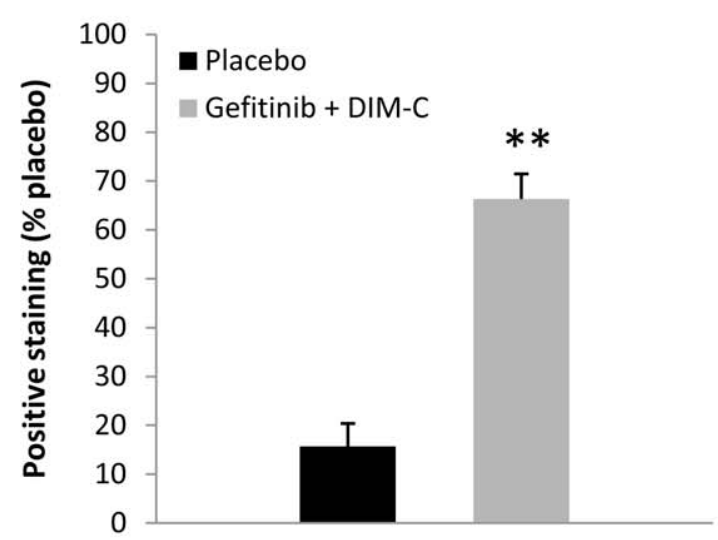

B

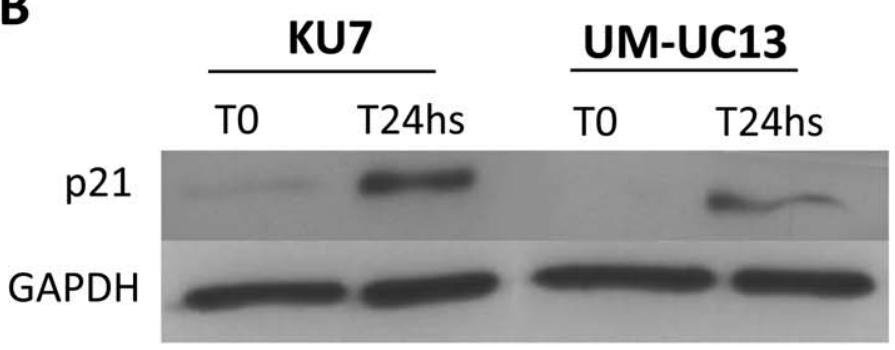

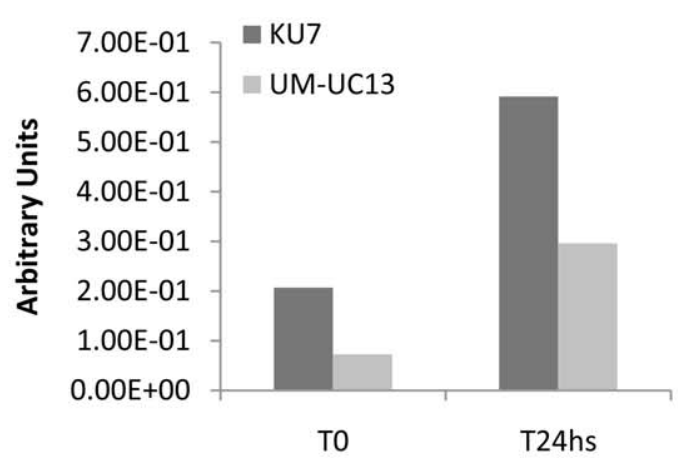

Figure 5. Effects of combination therapy on p21 expression in vivo and in vitro. (A) Immunohistochemistry (IHC) staining for p21 in tumor xenograft tissues. Mice were treated with placebo or combination therapy (Gefitinib $2 \mathrm{mg} /$ day, 5 times per week and DIM-C $60 \mathrm{mg} / \mathrm{Kg}, 3$ times per week). Graphic on the right side represents quantification of positive staining cells. (B) In vitro expression of p21 in Western blot of lysate cells treated with gefitinib $5 \mu \mathrm{M}$ and DIM-C $3 \mu \mathrm{M}$ for $24 \mathrm{hs}$. Graphic on the right side, represents quantification of p21 expression related to GAPDH. doi:10.1371/journal.pone.0055997.g005

\section{Effects of Treatment on Bladder Tumor Growth in vivo}

To evaluate whether these findings can be translated in vivo, nude mice were inoculated subcutaneously with relatively resistant bladder cancer cells (KU-7 cells). The mice were treated with targeted agents via oral gavage (PPAR $\gamma$-active DIM-Gs given $60 \mathrm{mg} / \mathrm{kg} 3$ times per week, gefitinib given $2 \mathrm{mg} /$ day 5 times per week, or both) for 4 weeks. As shown in Figure 4, tumor weights were markedly reduced in combined group in contrast to each drug alone when compared to control $(p<0.02)$. These findings suggest combined treatment has a better antitumor activity. Furthermore, gene expression profiling analysis of the bladder tumor xenografts, showed that several genes involved in cell cycle, cell death, cellular growth and proliferation were differently expressed in the combined treatment group as compared to the control group. (Table 1). Remarkably, cyclin-dependent Kinase inhibitor (CDKN1A or p21), which functions as a regulator of cell cycle progression at G1, was significantly upregulated (Fold change $2.6, p$ value $<0.02$ ) and this was validated by immunohistochemistry showing higher percentage of $\mathrm{p} 21$ positive cells in the combined arm in vivo (66\% vs $15 \%, \mathrm{p}<0.001)$ (Figure $5 \mathrm{~A})$ as well as in vitro (Figure 5B). Interestingly, it has been reported that PPAR $\gamma$ plays an important role mediating the differentiationdependent cascade expression of cyclin-dependent kinase inhibitors, thereby providing a molecular mechanism coupling growth arrest and adipocyte differentiation [22].
EGFR Inhibition Induces Gene Expression of PPAR $\gamma$ in a Dose-dependent Manner

We evaluated the effect of gefitinib on members of the PPAR $\gamma$ signalling axes. Two resistant cells (KU-7 and UM-UC13) were treated with different concentrations of EGFR inhibitor for $24 \mathrm{hs}$. PPAR $\gamma$ expression was determined by western blotting analyses as previously described. As shown in Figure 6A, a dramatic induction of PPAR $\gamma$ expression was observed in both cell lines, in a dose dependent manner, followed EGFR inhibition. Interestingly, a nuclear accumulation of PPAR $\gamma$ was also observed following its upregulation, which is in fact the active form of the receptor. (Figure 6B). These findings were confirmed in vivo, as seen in Figure 7, that shows PPAR $\gamma$ expression is higher among the xenograft tumors treated with gefitinib as compared to the placebo group. Of note, a nuclear staining was also observed, suggesting a nuclear translocation of $\operatorname{PPAR} \gamma$ following induction of its expression.

\section{Schedule-specific Efficacy of Combination Therapy}

If cells are sensitized to EGFR inhibition via induction of PPAR $\gamma$ expression, then one would expect that efficacy of combination therapy may also be significantly affected and improved by sequence of administration of gefitinib and DIM-C. In fact, we observed marked effect on proliferation among three relatively resistant and one sensitive cell lines to gefitinib (KU-7, 
Table 1. Analysis of molecular pathways and functions of the differentially expressed mRNAs of combined treatment compared to control group in bladder tumor xenografts.

\begin{tabular}{|c|c|c|}
\hline Molecules in Network & $P$ - Value & Top Functions \\
\hline $\begin{array}{l}\text { AXIN2, BACH2 CDKN1A, DUSP6, } \\
\text { DYRK1B, FOXO4, HAS2, MED16, MMP9, NCOR2, P38 MAPK, PDGF BB, } \\
\text { PLTP, SCGB1A1, STK39, SYNE1, } \\
\text { TNFSF11, VTN, XAF1 }\end{array}$ & $10 \mathrm{E}-38$ & $\begin{array}{l}\text { Cell Cycle, Tumor Morphology, } \\
\text { Cell Morphology }\end{array}$ \\
\hline $\begin{array}{l}\text { ALDH3A1, AMT, APOF, BDP1, } \\
\text { CCDC11, CDK18, CDKN1A, Cyclin D1/cdk4, NEURL2, NKAP, POMT1, } \\
\text { STX17, TAPBPL, VEZT }\end{array}$ & $10 \mathrm{E}-23$ & Cell Death, Genetic Disorder, \\
\hline $\begin{array}{l}\text { ARMCX3, CAMTA2, CDC42EP1, } \\
\text { FKBP2, HNRNPM, HSPBP1, HTR1E } \\
\text { KCNAB1, PIP4K2B, SRGAP2, TUSC3, } \\
\text { WDR17, ZFP91 }\end{array}$ & $10 \mathrm{E}-23$ & $\begin{array}{l}\text { Cell Cycle, Tumor Morphology, } \\
\text { Cellular Assembly and } \\
\text { Organization }\end{array}$ \\
\hline $\begin{array}{l}\text { DLX2, DLX3, EXOC1, FANCD2, } \\
\text { HAS2, HAUS6, HEATR3, IL1RAPL1, } \\
\text { MDN1, MYC, OSBPL1A, PROCKLE1, } \\
\text { PXMP4 }\end{array}$ & $10 \mathrm{E}-22$ & Gene Expression, Cancer and Immunological Disease \\
\hline $\begin{array}{l}\text { ARPC3, CFB, CFP, COL12A1, DDAH2, } \\
\text { KCNK6, KCTD7, KLHL4, PILRA, } \\
\text { PTPRB, SLC14A1, SMPDL3B }\end{array}$ & $10 \mathrm{E}-17$ & Cell Signaling, and Inflammatory Response \\
\hline MYCN & $10 \mathrm{E}-2$ & $\begin{array}{l}\text { Cancer, Cell Cycle, Cell-To-Cell } \\
\text { Signaling and Interaction }\end{array}$ \\
\hline
\end{tabular}

IPA analysis was performed in order to identify the molecular pathways and functions of the differentially expressed mRNAs of combined treatment compared to control group in bladder tumor xenografts. Most significantly enriched groups relating to molecular and cellular functions are shown. The networks were generated on the basis of the published literature and ranked by the P-value calculated by Fisher's exact Test.

doi:10.1371/journal.pone.0055997.t001

UM-UC3; UM-UM13) when cells were pre-treated with gefitinib for 24 hs to allow for induction of PPAR $\gamma$ expression compared to when the cells were simultaneous exposure to gefitinib and DIM-C (Figure 8). These findings strongly suggest PPAR $\gamma$ agonist could significantly sensitize UC cell lines, particularly those that were resistant to EGFR inhibition, in a schedule-specific manner and provide an excellent potential for combination therapy.

\section{C/EBP $\beta$ Expression After Gefitinib Induced-PPAR $\gamma$ \\ Expression}

Considerable evidence indicates that CGAAT/enhancer-binding protein beta $(\mathrm{C} / \mathrm{EBP} \beta)$ acts as a transcriptional activator for
PPAR $\gamma$ genes $[23,24]$. This belief is supported by the fact that the proximal of its promoters possess $\mathrm{C} / \mathrm{EBP}$ regulatory elements that are essential for transactivation of $\operatorname{PPAR} \gamma$ promoter-reporter transgenes. Here we report compelling evidence that sequential induction of PPAR $\gamma$ expression by EGFR inhibition is mediated by $\mathrm{C} / \mathrm{EBP} \beta$ (Figure 9). When cells were pre-treated with gefitinib at the same concentrations used to induce expression of PPAR $\gamma$, an increase in $\mathrm{C} / \mathrm{EBP} \beta$ was also observed suggesting gefitinib induced-PPAR $\gamma$ expression may be mediated by $\mathrm{C} / \mathrm{EBP} \beta$.
A

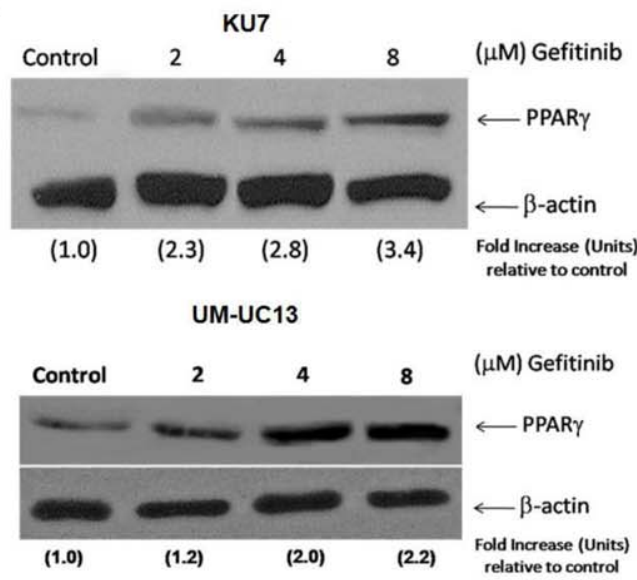

B

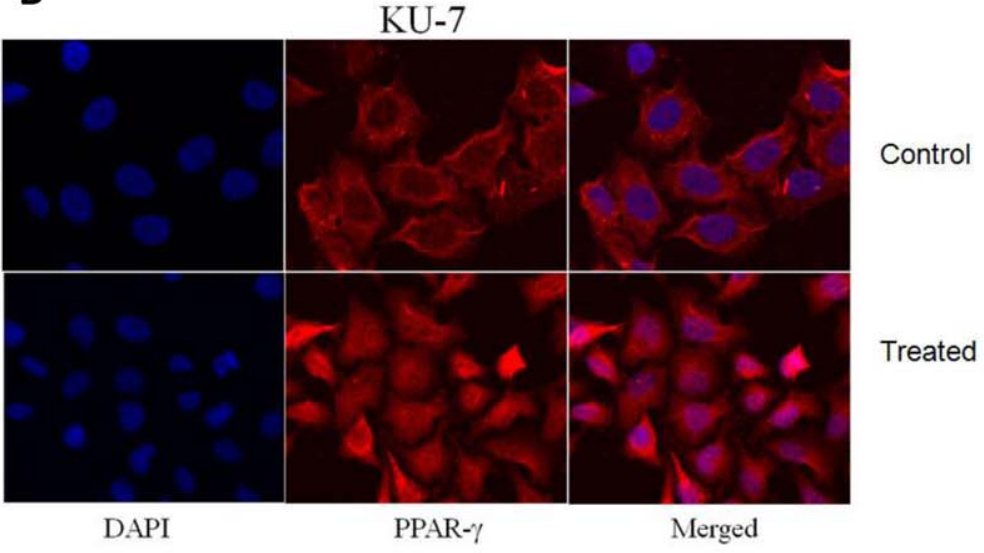

Figure 6. Induction of PPAR $\gamma$ expression in response to different concentrations of gefitinib. (A) Fold increase relative to control was determined after normalization with $\beta$-actin as external loading control. (B) Upregulation and nuclear accumulation of PPAR $\gamma$ following treatment with gefitinib (24 hs).

doi:10.1371/journal.pone.0055997.g006 


\section{Placebo}

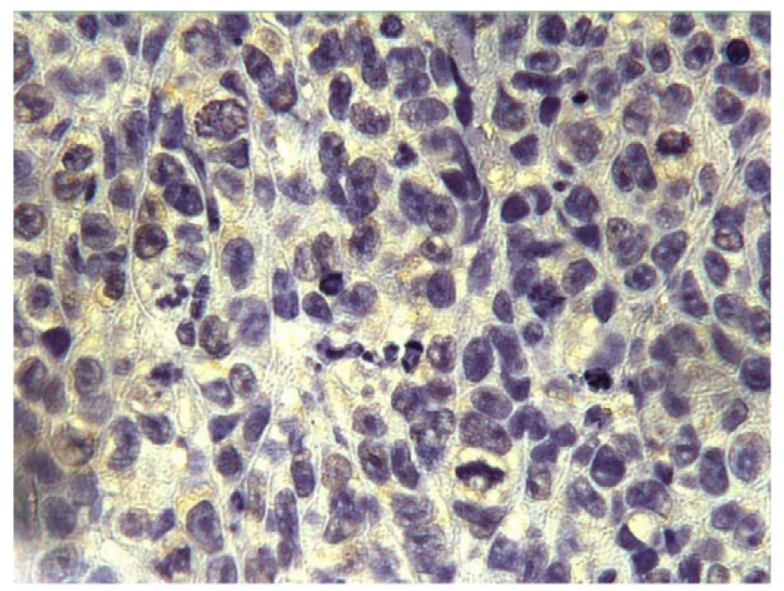

\section{Gefitinib}

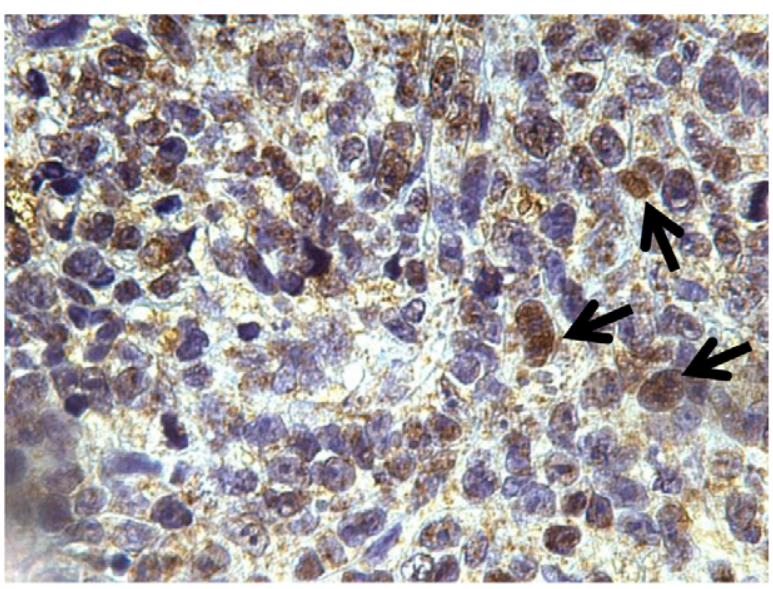

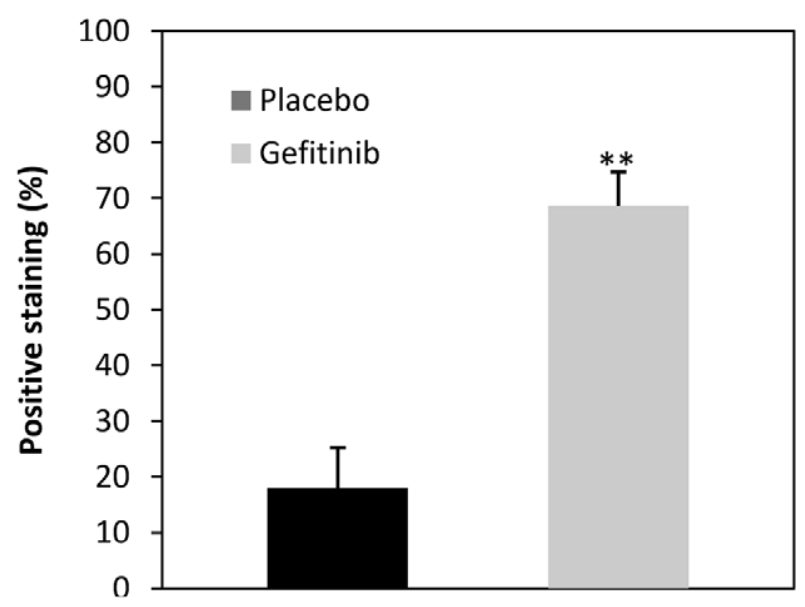

Figure 7. Immunohistochemistry (IHC) staining for PPAR $\gamma$ in tumor xenograft tissues Mice were treated with placebo or gefitinib (Gefitinib 2 mg/day, 5 times per week). Graphic on the lower level represents quantification of positive staining cells. Black arrows indicate nuclear staining.

doi:10.1371/journal.pone.0055997.g007

\section{Discussion}

Results from a large body of preclinical studies and clinical trials suggest that targeting EGFR represents a significant contribution to cancer therapy. However, the issue of constitutive resistance in a large number of patients and the development of acquired resistance in the responders remains an unexplored subject of investigation. Cancer cell resistance to EGFR antagonists could be due to several reasons, such as genetic alterations, which enable them to have an intrinsic resistance to anticancer drugs. In addition, several different molecular changes important in EGFR dependent or -independent cellular signalling pathways could be responsible for the development of resistance to these inhibitors. For instance, we have previously shown uncoupling of EGFR with mitogenic pathways can cause resistance to EGFR antagonists [7]. Currently, combined therapy has become a breakthrough in treating cancer. In a range of tumor entities, such approach has produced impressive results. Combination therapy of PPAR $\gamma$ agonists and other agents has been shown to be more effective than using either agent alone. [25,26]. In bladder cancer cells in vitro and in bladder tumor in vivo, we demonstrated that $\operatorname{PPAR} \gamma$ active DIM-Cs showed significant anti-tumorigenic activity and were more potent inhibitors of bladder cancer growth when compared with rosiglitazone, the currently used synthetic PPAR $\gamma$ agonist [16]. Taken together, combined targeting of both EGFR and PPAR $\gamma$ axes can reveal promising molecules to target in bladder cancer. However, our results have shown that human urothelial cancer cell lines display marked heterogeneity towards sensitivity to EGFR inhibitors. Of high interest, the levels of expression of EGFR and PPAR $\gamma$ varied significantly among the different cell lines but did not correlate with stage of disease (range from superficial papillary to invasive to metastatic tumors). Furthermore, this correlation was not perfect as well to sensitivity either to EGFR inhibitor or PPAR $\gamma$ agonist with exception of UM-UC5 that shows high levels of EGFR expression and display high sensitivity to EGFR inhibitor. These findings corroborate results from other groups that have reported, in a panel of 17 human bladder cancer cell lines, that despite the strong correlation among gefitinib-responsiveness, EGFR surface expression and p27Kipl protein expression in the most responsive lines, gefitinibresponsiveness was not as tightly linked to surface EGFR expression within the panel of cell lines as a whole [27]. These 


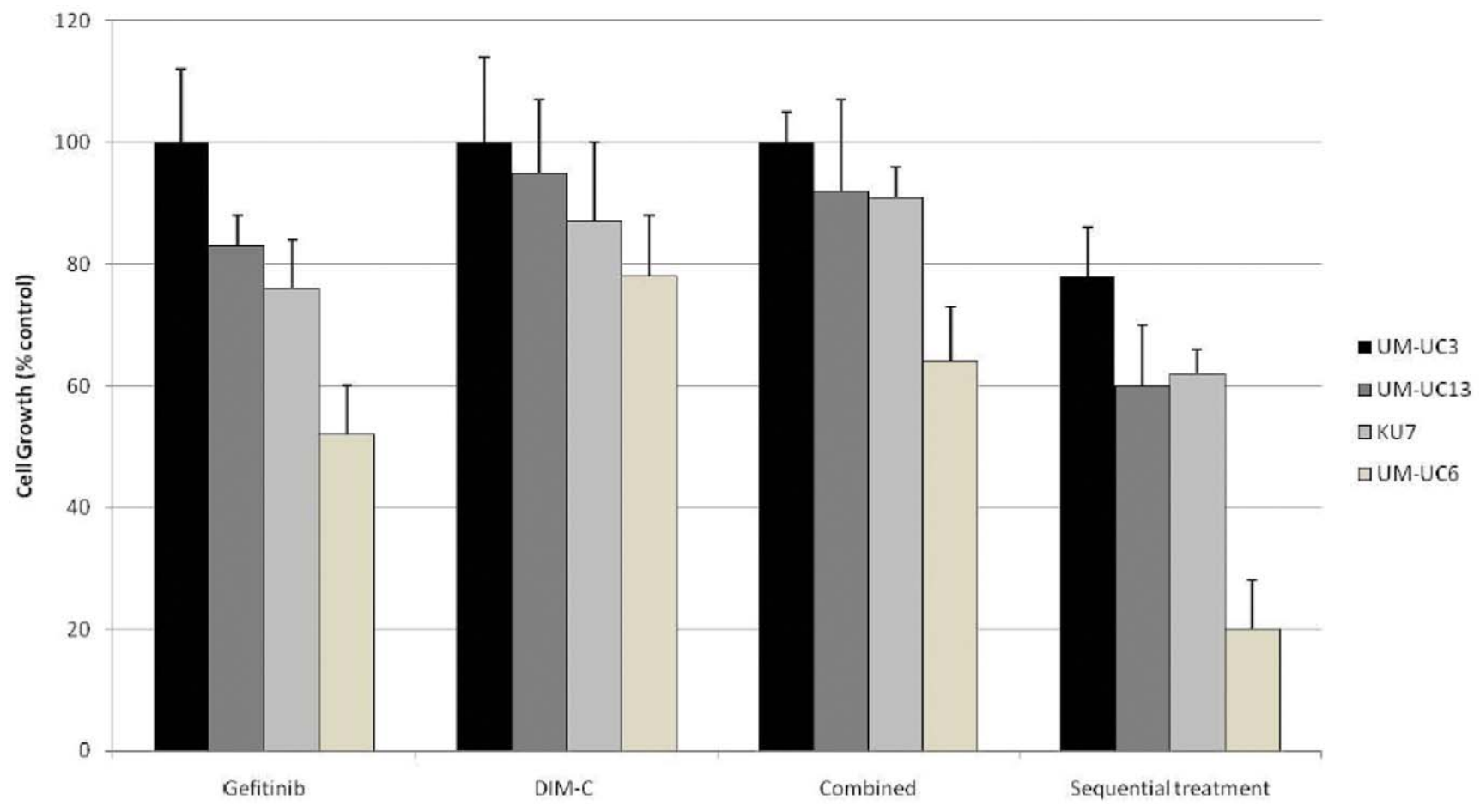

Figure 8. Schedule-specific efficacy of combination therapy. Three relatively resistant cell lines to gefitinib (UM-UC3, UM-UC13, and KU-7) and one sensitive (UM-UC6). Growth (MTT assays) after 48 hs treatment. Gefitinib: $2 \mu$ M. DIM-C: $2 \mu \mathrm{M}$. doi:10.1371/journal.pone.0055997.g008

results are remarkable but remain unclear whether baseline expression could predict EGFR dependent growth in bladder cancer. Conversely, when two resistant cell lines (KU-7 and UMUC13) were treated with fixed-ratio of different fractions of GI50 of each drug alone (gefitinib or DIM-C), combination therapy potentially exerts additive inhibition of $\mathrm{UC}$ cell proliferation. These results provided further insight into the potential of combined therapy to overcome resistance to either drug alone, particularly to EGFR inhibitor. Indeed, our in vivo findings, showed positively the effects of combined EGFR inhibitors and PPAR $\gamma$ agonists on the growth of human urothelial tumors. In fact, xenografts nude mice with the relatively resistant bladder cancer cells (KU-7 cells) showed a markedly reduced tumor weight in combined group, in contrast to each treatment alone when compared to control. These findings indicate that even relatively resistant cells, in vitro, demonstrated sensitivity in vivo in the combined treatment, suggesting PPAR $\gamma$ agonist could potentially be used to sensitize bladder cancer cell lines that were resistant to EGFR inhibition.

Recently, curcumin was shown to induce PPAR $\gamma$ expression in hepatic stellate cells and inhibit cell proliferation potentially via inhibiting EGFR activation [28]. In this study, Zhou et al, reported that interruption of the PDGF and EGF signalling pathways by curcumin, stimulates gene expression of PPAR $\gamma$ in activated Hepatic Stellate Cells (HSC), leading to the reduction in cell growth, including induction of cell arrest and apoptosis. Similarly, we observed an induction of PPAR $\gamma$ expression upon inhibition of EGFR in resistant KU-7 and UM-UC13 cells. This was an attractive result, since induction of PPAR $\gamma$ expression was observed in a dose dependent manner, and was followed by a nuclear accumulation of PPAR $\gamma$, which is, in fact, the functional form of the receptor. Our novel observation reflects that efficacy of
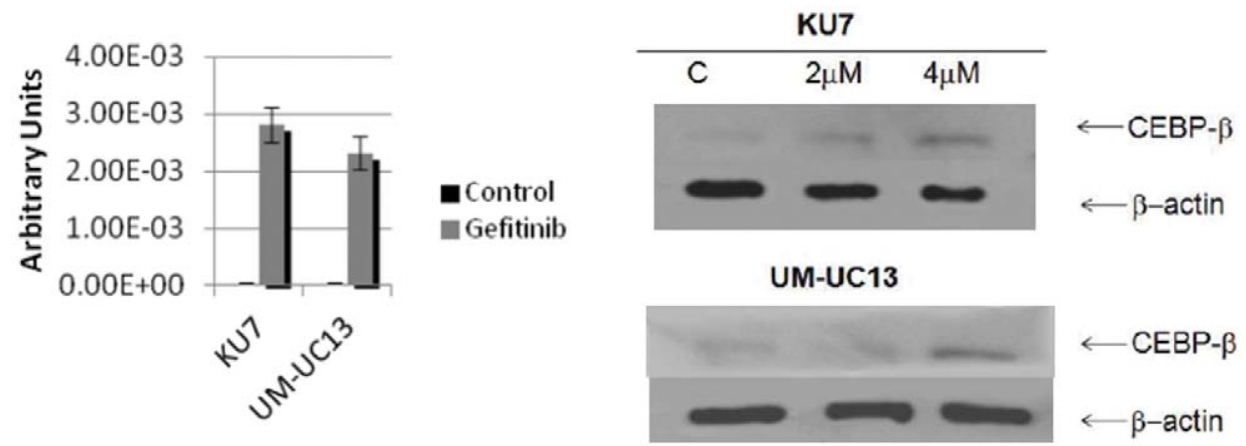

Figure 9. mRNA expression of CEBP $\beta$ after treatment with gefitinib. (A) RT-PCR of cells treated with gefitinib (B) Western blot of CEBP $\beta$ expression in KU-7 and UM-UC-13 cell lines in response to different concentrations of gefitinib. doi:10.1371/journal.pone.0055997.g009 
combination therapy may also be significantly affected and improved by sequenced administration of gefitinib and PPAR $\gamma$ agonist. In reality, PPAR $\gamma$ agonist markedly sensitized bladder cancer cell lines, particularly those that were resistant to EGFR inhibition, in a schedule-specific manner, suggesting it can be an excellent alternative when cells are resistant to the aforementioned monotherapies. The mechanism of induction of PPAR $\gamma$ gene expression by gefitinib is still not clear. During adipogenesis, considerable evidences indicate that $\mathrm{CEBP} / \beta$ act as a transcriptional activator of PPAR $\gamma$ genes [23]. This belief is supported by the fact that proximal promoters of PPAR $\gamma$ posses $\mathrm{C} / \mathrm{EBP}$ regulatory elements essential for its transactivation. Moreover, it has been shown that $\mathrm{CEBP} / \beta$ is expressed at early stage subsequently to treatment with differentiation inducers [29] followed by expression of PPAR $\gamma$. Indeed, our findings shows EGFR inhibition induced CEBP/ $\beta$ expression and interestingly, its upregulation was also observed at early stage after gefitinib treatment, a process very similar to activation of adipogenic genes during differentiation, and which precedes induction of PPAR $\gamma$

\section{References}

1. Ciardiello F (2000) Epidermal growth factor receptor tyrosine kinase inhibitors as anticancer agents. Drugs 60 Suppl 1: 25-32; discussion 41-22.

2. Mendelsohn J, Dinney CP (2001) The Willet F. Whitmore, Jr., Lectureship: blockade of epidermal growth factor receptors as anticancer therapy. J Urol 165: 1152-1157.

3. Paez JG, Janne PA, Lee JC, Tracy S, Greulich H, et al. (2004) EGFR mutations in lung cancer: correlation with clinical response to gefitinib therapy. Science 304: $1497-1500$

4. Lynch TJ, Bell DW, Sordella R, Gurubhagavatula S, Okimoto RA, et al. (2004) Activating mutations in the epidermal growth factor receptor underlying responsiveness of non-small-cell lung cancer to gefitinib. N Engl J Med 350: 2129-2139.

5. Blehm KN, Spiess PE, Bondaruk JE, Dujka ME, Villares GJ, et al. (2006) Mutations within the kinase domain and truncations of the epidermal growth factor receptor are rare events in bladder cancer: implications for therapy. Clin Cancer Res 12: 4671-4677.

6. Kassouf W, Black PC, Tuziak T, Bondaruk J, Lee S, et al. (2008) Distinctive expression pattern of ErbB family receptors signifies an aggressive variant of bladder cancer. J Urol 179: 353-358.

7. Kassouf W, Dinney CP, Brown G, McConkey DJ, Diehl AJ, et al. (2005) Uncoupling between epidermal growth factor receptor and downstream signals defines resistance to the antiproliferative effect of Gefitinib in bladder cancer cells. Cancer Res 65: 10524-10535.

8. Fajas L, Auboeuf D, Raspe E, Schoonjans K, Lefebvre AM, et al. (1997) The organization, promoter analysis, and expression of the human PPARgamma gene. J Biol Chem 272: 18779-18789.

9. Motomura W, Okumura T, Takahashi N, Obara T, Kohgo Y (2000) Activation of peroxisome proliferator-activated receptor gamma by troglitazone inhibits cell growth through the increase of $\mathrm{p} 27 \mathrm{KiP} 1$ in human. Pancreatic carcinoma cells. Cancer Res 60: 5558-5564.

10. Mansure JJ, Nassim R, Kassouf W (2009) Peroxisome proliferator-activated receptor gamma in bladder cancer: a promising therapeutic target. Cancer Biol Ther 8: 6-15.

11. Guan YF, Zhang YH, Breyer RM, Davis L, Breyer MD (1999) Expression of peroxisome proliferator-activated receptor gamma (PPARgamma) in human transitional bladder cancer and its role in inducing cell death. Neoplasia 1: 330339.

12. Suzuki T, Nakagawa T, Endo H, Mitsudomi T, Masuda A, et al. (2003) The sensitivity of lung cancer cell lines to the EGFR-selective tyrosine kinase inhibitor ZD1839 ('Iressa') is not related to the expression of EGFR or HER-2 or to K-ras gene status. Lung Cancer 42: 35-41.

13. Burgermeister E, Tencer L, Liscovitch M (2003) Peroxisome proliferatoractivated receptor-gamma upregulates caveolin-1 and caveolin-2 expression in human carcinoma cells. Oncogene 22: 3888-3900.

14. Xin X, Yang S, Kowalski J, Gerritsen ME (1999) Peroxisome proliferatoractivated receptor gamma ligands are potent inhibitors of angiogenesis in vitro and in vivo. J Biol Chem 274: 9116-9121.

15. Bishop-Bailey D, Hla T (1999) Endothelial cell apoptosis induced by the peroxisome proliferator-activated receptor (PPAR) ligand 15-deoxy-Delta 12, 14prostaglandin J2. J Biol Chem 274: 17042-17048.

16. Kassouf W, Chintharlapalli S, Abdelrahim M, Nelkin G, Safe S, et al. (2006) Inhibition of bladder tumor growth by 1,1-bis(3'-indolyl)-1-(p-substitutedphenyl)methanes: a new class of peroxisome proliferator-activated receptor gamma agonists. Cancer Res 66: 412-418. gene expression. However, future studies are needed in order to determine the direct role of $\mathrm{C} / \mathrm{EBP} \beta$ in the induction of PPAR $\gamma$ expression mediated by gefitinib. When interpreting our results, it is important to recognize the limitations of preclinical studies. Additionally, long-term use of PPAR $\gamma$ agonist such as pioglitazone has been associated with risk of bladder cancer while short-term use has shown no association [30,31]. Therefore, despite our promising findings show PPAR $\gamma$ agonists are more effective in combination therapy and particularly render bladder tumor sensitive to EGFR inhibition, a better understanding of the mechanism of activated PPAR $\gamma$ and EGFR inhibition is needed to evaluate the benefits from such therapy in future clinical applications.

\section{Author Contributions}

Conceived and designed the experiments: JJM SG WK. Performed the experiments: JJM RN KS SA JR. Analyzed the data: JJM SC WK. Wrote the paper: JJM SC WK
17. Lee SY, Hur GY, Jung KH, Jung HC, Kim JH, et al. (2006) PPAR-gamma agonist increase gefitinib's antitumor activity through PTEN expression. Lung Cancer 51: 297-301.

18. Zhou Y, Zheng S, Lin J, Zhang QJ, Chen A (2007) The interruption of the PDGF and EGF signaling pathways by curcumin stimulates gene expression of PPARgamma in rat activated hepatic stellate cell in vitro. Lab Invest 87: 488498.

19. Dinney CP, Fishbeck R, Singh RK, Eve B, Pathak S, et al. (1995) Isolation and characterization of metastatic variants from human transitional cell carcinoma passaged by orthotopic implantation in athymic nude mice. J Urol 154: 1532 1538.

20. Sabichi A, Keyhani A, Tanaka N, Delacerda J, Lee IL, et al. (2006) Characterization of a panel of cell lines derived from urothelial neoplasms: genetic alterations, growth in vivo and the relationship of adenoviral mediated gene transfer to coxsackie adenovirus receptor expression. J Urol 175: 11331137

21. Ono M, Kuwano M (2006) Molecular mechanisms of epidermal growth factor receptor (EGFR) activation and response to gefitinib and other EGFR-targeting drugs. Clin Cancer Res 12: 7242-7251.

22. Morrison RF, Farmer SR (1999) Role of PPARgamma in regulating a cascade expression of cyclin-dependent kinase inhibitors, p18(INK4c) and p21(Wafl/ Cip1), during adipogenesis. J Biol Chem 274: 17088-17097.

23. Zhu Y, Qi C, Korenberg JR, Chen XN, Noya D, et al. (1995) Structural organization of mouse peroxisome proliferator-activated receptor gamma (mPPAR gamma) gene: alternative promoter use and different splicing yield two mPPAR gamma isoforms. Proc Natl Acad Sci U S A 92: 7921-7925.

24. Pettaway CA, Pisters LL, Dinney CP, Jularbal F, Swanson DA, et al. (1995) Sentinel lymph node dissection for penile carcinoma: the M. D. Anderson Cancer Center experience. J Urol 154: 1999-2003.

25. Emmans VC, Rodway HA, Hunt AN, Lillycrop KA (2004) Regulation of cellular processes by PPARgamma ligands in neuroblastoma cells is modulated by the level of retinoblastoma protein expression. Biochem Soc Trans 32: 840 842.

26. Hau P, Kunz-Schughart L, Bogdahn U, Baumgart U, Hirschmann B, et al. (2007) Low-dose chemotherapy in combination with COX-2 inhibitors and PPAR-gamma agonists in recurrent high-grade gliomas - a phase II study. Oncology 73: 21-25.

27. Shrader M, Pino MS, Brown G, Black P, Adam L, et al. (2007) Molecular correlates of gefitinib responsiveness in human bladder cancer cells. Mol Cancer Ther 6: 277-285.

28. Lin J, Chen A (2008) Activation of peroxisome proliferator-activated receptorgamma by curcumin blocks the signaling pathways for PDGF and EGF in hepatic stellate cells. Lab Invest 88: 529-540.

29. Tang QQ Lane MD (1999) Activation and centromeric localization of CCAAT/enhancer-binding proteins during the mitotic clonal expansion of adipocyte differentiation. Genes Dev 13: 2231-2241.

30. Lewis JD, Ferrara A, Peng T, Hedderson M, Bilker WB, et al. (2011) Risk of bladder cancer among diabetic patients treated with pioglitazone: interim report of a longitudinal cohort study. Diabetes Care 34: 916-922.

31. Dormandy J, Bhattacharya M, van Troostenburg de Bruyn AR (2009) Safety and tolerability of pioglitazone in high-risk patients with type 2 diabetes: an overview of data from PROactive. Drug Saf 32: 187-202. 